\title{
Most relevant sources of indoor particles in children's rooms and respiratory health effects of size-segregated particles
}

\author{
U. Franck ${ }^{1}$, S. Röder ${ }^{1}$, U. Schlink ${ }^{1}$, M. Borte ${ }^{2}$, \\ O. Herbarth ${ }^{3}$ \& I. Lehmann ${ }^{1}$ \\ ${ }^{1}$ Helmholtz Centre for Environmental Research - UFZ, Leipzig, Germany \\ ${ }^{2}$ Children's Hospital, Municipal Hospital "St. Georg”, Leipzig, Germany \\ ${ }^{3}$ University of Leipzig, Faculty of Medicine, \\ Department Environmental Medicine and Hygiene, Germany
}

\begin{abstract}
Numerous epidemiological studies have provided evidence of an association between elevated outdoor particulate air pollution and adverse health effects. Young children typically spend majority of time at home and indoors. There is still limited knowledge on indoor particles sources and especially on their health effects. Even insights into the influence of differently sized indoor particles on human health are extremely rare. We studied these correlations for three year aged children.

Information on possible particle sources (exposure to environmental tobacco smoke, type of heating, and traffic at place of residence as well as in front of the children's room) and respiratory outcomes were obtained from questionnaires. Short-term measurements of particle mass and number concentrations within different particle size fractions were carried out in children's rooms. Indoor concentrations of these size fractions were correlated with possible sources of indoor particles and with respiratory health impacts.

Daily smoking, smoking more than 5 cigarettes per day at home and traffic density in front of the window of children's room were found to be related to indoor exposure by particles of different diameters. High indoor particle exposures were associated with an increased risk for the development of obstructive bronchitis and in some extent of non-obstructive bronchitis. The strongest impact was associated to mass concentration of particles $<1 \mu \mathrm{m}$ and
\end{abstract}


the number concentration of particles $>0.5 \mu \mathrm{m}$. The risk increases still remain significant if tested for stability changing the number of adjustment variables or omitting randomly selected cases, respectively.

Our results show significant associations between exposure to differently sized indoor particles and the risks for respiratory diseases in young children. Short-term measurements within epidemiological studies can help to assess the health risks of indoor particles with different sizes.

Keywords: children's health, respiratory effects, indoor air, particle fractions.

\section{Introduction}

Recent studies have reported links between exposure to airborne particles and a whole range of respiratory symptoms and pulmonary function deficits. Airborne particles do not constitute a uniform population. Therefore, various types of particulate air pollution have been addressed in epidemiological studies. Former studies mainly used particle mass. Typical predictors for health impacts were TSP (mass of total suspended matter) and PM10 (mass of particulate matter with an effective aerodynamic diameter less than $10 \mu \mathrm{m})$. In recent years, many studies have targeted fine particulate matter, i.e. particles with an aerodynamic diameter less than $2.5 \mu \mathrm{m}$ (PM2.5). In comparison to these studies, only very few studies have paid special attention to the ill-health effects of smaller particles such as submicrometer and ultrafine particles (smaller than $1 \mu \mathrm{m}$ and $100 \mathrm{~nm}$, respectively).

The concentration of submicrometer particles is rather characterized by number concentration than mass concentrations. Therefore, epidemiologic studies use number instead of mass concentration for effect assessment of these particles.

Measurements of size-resolved particle exposure are rather sophisticated and expensive. Hence, most epidemiologic studies use outdoor particle mass and number concentrations as a surrogate of personal exposure. In most countries, people spent the majority of their time indoors. For example, German children are $\sim 87 \%$ of their time indoors and $\sim 66 \%$ of their time at parental home [1].

The number of epidemiological studies is highest for effects of exposure to outdoor particle mass concentrations, followed by outdoor particle number concentrations. Only few studies addressed indoor particle mass and sill less indoor particle number concentrations. Furthermore, only few findings exist on health effects of airborne particles on children. Delfino et al. [2] measured over 10 days the concentrations of PM2.5, EC, OC and NO2 with personal samplers. They concluded that PM2.5 alone may not sufficiently represent causal pollutant components from fuel combustion.

In smoking households, environmental tobacco smoke (ETS) will be often an important component of particulate indoor air pollution. There are many indications that indoor smoking can increase risks for bronchitis, and other respiratory outcomes $[3,4]$. Heating and cooking may also be important indoor particle sources. Indoor gas cooking increase particle concentrations and is suspected to produce respiratory symptoms in children $[5,6]$. These indoor 
studies, however, examine health effects in relation to emission sources. They do not measured particle concentrations and also not different size fractions of particles in particular including submicron particles. An additional important source of indoor particles is outdoor particles [7].

Therefore, this study had the following aims

- to monitor typical indoor concentrations of different particle size fractions

- to relate the indoor particle concentrations to particle sources

- to assess respiratory health effects of indoor particles on children, taking different particle sizes into account.

\section{Material and methods}

The present analysis was carried out as a part of the population-based LISAstudy. The design is described in $[8,9]$. Neonates, born between 12/1997 and 1/1999 in four German cities were recruited for this study. Participation in the study was voluntary. Informed consent was obtained from the parents of all children. The study was approved by the Ethics Committee of the University of Leipzig. Only healthy term neonates were included. New born children whose mothers suffered from autoimmune or infectious diseases disorders during gestation were excluded. Children from this study were followed up regularly with questionnaire evaluations, clinical examinations and indoor measurements. The questionnaires have been answered by mother and/or father. Before analyses, the questionnaires have been controlled for conflicting answers. Measurements, clinical investigations and shipment of questionnaires took place \pm 4 weeks around the third birthday of the participating child. 579 3-year old children from the city of Leipzig participated in the study. The city is located in the Leipzig lowlands in Central Germany. Leipzig has around 500,000 inhabitants and no heavy industry. Traffic, regional as well as long-distance transport and heating are dominating sources of airborne outdoor particles. In a randomly selected subgroup from the cohort that have been recruited in city of Leipzig a variety of extensive measurements including airborne particles were carried out at the age of three. Concentrations of different particle size fractions were measured at home in the children's room or in the room where the children mostly stay. In the subgroup with particle measurements, there were no missing answers among those which we used for this statistical evaluation. The subcohort used for this study included 129 children. This cohort did not include twins.

Particle concentrations were measured carried during weekdays, between 9:15 A.M and 7:45 P.M. In each apartment one measurement over ten minutes was performed. The parents have been instructed to close the windows at least two hours before the measurements. The mass concentrations of airborne particles were determined with the DustTrak 8520 device (TSI Incorporated, Shoreview, USA). Using different inlets, the DustTrak devices could be used for particle mass concentrations PM10, PM2.5 and PM1. The number concentrations of particles were measured with an airborne particle counter (APC PLUS Biotest HYCON, Biotest Diagnostics Corporation, Rockaway, USA). The counter 
measured particles larger than $0.3 \mu \mathrm{m}, 0.5 \mu \mathrm{m}, 1.0 \mu \mathrm{m}$ and $5.0 \mu \mathrm{m}$. Additionally, a condensation particle counter was used for determination of total number concentrations (CPC3007, TSI Incorporated, Shoreview, USA). All devices of one type were checked in parallel in the laboratory for measuring similar concentrations $( \pm 5- \pm 10 \%)$ at identical measuring conditions. The measuring devices were placed in the centre of the room in a height of 70-90 cm above floor in the children's room or alternatively in the room where the children preferentially stay. Nobody was present during the measurements. The door of the room was kept close. Similar, but repeated measurements were carried out in one selected room under the same measuring conditions as in the study to demonstrate that short-term measurements are able to reflect typical indoor particle concentrations (data not shown).

Questionnaires were used to get information on possible particle sources (see Table 2). Data from questionnaires comprised information on smoking in the apartment, types of cooking and heating and traffic density in the vicinity of the apartment. Indoor exposure of children to ETS was assessed basing on questionnaires. It was asked for information focusing on smoking in the dwelling differing between i) daily, ii) less than daily and iii) never. Furthermore, we get information on number of cigarettes per day smoked indoors. For epidemiological analysis, we differed between 0 cigarettes, 1-5 cigarettes, and more than 5 cigarettes per day.

Statistical analyses were carried out using the program package Statistica (Version 7.1, Statsoft Europe, Hamburg, Germany). Significant differences between subgroups with varying exposure conditions were identified by the nonparametric Mann-Whitney U-test. Health risks were ranked by odds ratios (OR) using logistic regression models with $95 \%$ confidence interval (CI) for the association between indoor particle concentrations and respiratory outcomes. The $75^{\text {th }}$ and $90^{\text {th }}$ percentiles of the measured indoor particle concentrations were used to define the group of children with elevated / highest exposure to a specific mass or number concentration of the size fractions of particles. Odds ratios were adjusted for gender, atopic family anamnesis (mother, father or both parents), visible mould in the apartment number of persons living in the apartment, and season of birth. For season of birth we differed between summer months (AprilSeptember) and winter months (October-March).

\section{Results and discussion}

Table 1 describes the study population. With respect to the considered covariates there was no difference between the subcohort of this study $(n=129)$ and the total LISA cohort from Leipzig $(n=579)$. The incidences for obstructive bronchitis, asthma, and wheezing symptoms were similar in the LISA Leipzig cohort and the subcohort with particle measurements (table 1). Due to the low case numbers for asthma and wheezing without fever only bronchitis and wheezing with fever were included in the present analyses. 
Table 1: Comparison of analyzed subcohort and all children of the LISA study in Leipzig.

\begin{tabular}{|c|c|c|c|}
\hline & $\begin{array}{c}\text { Analyzed } \\
\text { Subcohort } \\
\text { n (\%) }\end{array}$ & $\begin{array}{c}\text { Total LISA } \\
\text { cohort of Leipzig } \\
\text { n (\%) }\end{array}$ \\
\hline & & $\mathrm{N}=129$ & $\mathrm{~N}=579$ \\
\hline \multirow{3}{*}{$\begin{array}{l}\text { Atopy } \\
\text { family } \\
\text { history }\end{array}$} & Negative & $70(54.3 \%)$ & $323(55.8 \%)$ \\
\hline & Single positive & $47(36.4 \%)$ & $199(34.4 \%)$ \\
\hline & Double positive & $12(9.3 \%)$ & $57(9.8 \%)$ \\
\hline \multirow[t]{2}{*}{ Season } & Winter & $71(55.0 \%)$ & $303(52.3 \%)$ \\
\hline & Summer & $58(45.0 \%)$ & $276(47.7 \%)$ \\
\hline \multirow[t]{2}{*}{ Gender } & Female & $59(45.7 \%)$ & $295(51.0 \%)$ \\
\hline & Male & $70(54.3 \%)$ & $284(49.0 \%)$ \\
\hline \multirow[t]{2}{*}{ Mould } & No & $98(76.0 \%)$ & $416(71.8 \%)$ \\
\hline & Yes & $31(24.0 \%)$ & $156(26.9 \%)$ \\
\hline \multirow{4}{*}{$\begin{array}{l}\text { Number of } \\
\text { persons }\end{array}$} & 2 & $8(6.2 \%)$ & $35(5.9 \%)$ \\
\hline & 3 & $53(41.1 \%)$ & $222(38.3 \%)$ \\
\hline & 4 & $55(42.6 \%)$ & $258(44.6 \%)$ \\
\hline & $>4$ & $13(10.1 \%)$ & $56(11.2 \%)$ \\
\hline \multirow{3}{*}{$\begin{array}{l}\text { Doctor's } \\
\text { diagnosis }\end{array}$} & Bronchitis with fever & $37(28.7 \%)$ & $171(29.5 \%)$ \\
\hline & $\begin{array}{l}\text { Obstructive bronchitis - } \\
\text { with fever }\end{array}$ & $17(13.2 \%)$ & $78(13.5 \%)$ \\
\hline & - with or without fever & $22(17.1 \%)$ & $104(18.0 \%)$ \\
\hline
\end{tabular}

Table 2 lists typical particle sources according to the questionnaires. $18.6 \%$ of the children were daily exposed to ETS at home. Classification according to the number of cigarettes smoked by parents and other persons in the apartment showed that nineteen children were exposed to 1-5 cigarettes, thirteen to more than 5 cigarettes per day.

Gas heating was the most frequent heating source $(34.9 \%)$, followed by electrical heating $(12.4 \%)$, while oil heating and coal burning stoves were rather unusual. Approximately one fourth $(26.4 \%)$ of the children lived in apartments located in a street with high traffic density. In $12.4 \%$ of all apartments the window of the children's rooms was directed to a street with high traffic density.

Table 3 demonstrates the variation particle concentration within the study population. In $50 \%$ of children's rooms we measured total particle number concentrations between $\sim 9,000$ and 16,000 particles $/ \mathrm{cm}^{3}$ and PM2.5 concentrations between 20 and $66 \mu \mathrm{g} / \mathrm{m}^{3}$. Around 54\% of PM10 mass is PM2.5. PM1 contributes around $96 \%$ to PM2.5. 
Table 2: $\quad$ Sources of particles according to questionnaires $(\mathrm{n}-$ number of cases).

\begin{tabular}{|c|c|c|c|}
\hline \multicolumn{2}{|l|}{ Variables } & \multirow{2}{*}{$\begin{array}{l}\text { Analyzed } \\
\text { study cohort } \\
\text { n (\%) }\end{array}$} & \multirow{2}{*}{$\begin{array}{ll}\begin{array}{l}\text { Total LISA } \\
\text { cohort }\end{array} \\
\text { n }(\%)\end{array}$} \\
\hline & & & \\
\hline & & $\mathrm{N}=129$ & $\mathrm{~N}=579$ \\
\hline \multirow{2}{*}{$\begin{array}{l}\text { Indoor } \\
\text { smoking }\end{array}$} & daily & $24(18.6 \%)$ & $87(15.0 \%)$ \\
\hline & no or rarely & $105(81.4 \%)$ & $492(85.0 \%)$ \\
\hline \multirow{3}{*}{$\begin{array}{l}\text { Daily } \\
\text { smoked } \\
\text { cigarettes }\end{array}$} & 0 & $97(75.2 \%)$ & $448(77.4 \%)$ \\
\hline & $1-5$ & $19(14.7 \%)$ & $87(15.0 \%)$ \\
\hline & $>5$ & $13(10.1 \%)$ & $44(7.6 \%)$ \\
\hline \multirow{4}{*}{$\begin{array}{l}\text { Heating } \\
\text { type }\end{array}$} & Coal burning stove & $3(2.3 \%)$ & $18(3.2 \%)$ \\
\hline & Indoor gas heating & $45(34.9 \%)$ & $141(24.4 \%)$ \\
\hline & Indoor oil heating & $3(2.3 \%)$ & $27(4.7 \%)$ \\
\hline & Electrical heating & $16(12.4 \%)$ & $83(14.5 \%)$ \\
\hline \multirow[t]{6}{*}{ Traffic } & \multicolumn{3}{|c|}{ Living in a street with high traffic density } \\
\hline & yes & $34(26.4 \%)$ & $141(24.4 \%)$ \\
\hline & no & $95(73.6 \%)$ & $438(75.6 \%)$ \\
\hline & \multicolumn{3}{|c|}{$\begin{array}{l}\text { Children's room with window to a street with high traffic } \\
\text { density }\end{array}$} \\
\hline & yes & $16(12.4 \%)$ & $63(10.9 \%)$ \\
\hline & no & $113(87.6 \%)$ & $516(89.1 \%)$ \\
\hline
\end{tabular}

For technical reasons, the total particle number concentration could be measured in 59 apartments, only. For statistical reasons, this parameter was not included into the investigation of particle health effects.

The importance of sources of indoor particles has been assessed relating questionnaire data with measured particle concentrations. For identification of potential indoor particle sources we used questionnaire data on for smoking habits of adults in the apartment, heating types, and traffic density.

Smoking habits were classified by the questionnaire answer on "daily smoking vs. no/rarely smoking" and by summing the numbers of cigarettes which have been smoked per day in the apartment.

Table 4 demonstrates the influence of potential sources of indoor particles on measured particle. Indoor smoking behaviour has a significant influence on particle concentrations, but also outdoor traffic density. Smoking of more than 5 cigarettes per day resulted in a strong risk of children for being exposed to high particle number concentrations particles of all measured size fractions compared 
Table 3: $\quad$ Statistics of indoor particle measurements $(\mathrm{N}=129)$.

\begin{tabular}{|c|c|c|c|c|c|c|}
\hline $\begin{array}{c}\text { Size } \\
\text { fraction }\end{array}$ & \multicolumn{7}{|c|}{ Percentile } & Mean \\
\hline & 10 th & 25th & 50th & 75 th & 90 th & \\
\hline \multicolumn{7}{|c|}{ total number concentration $\left(1 / \mathrm{cm}^{3}\right)^{*}$} \\
\hline & 4,057 & 6,023 & 9,075 & 16,057 & 30,348 & 15,96 \\
\hline \multicolumn{7}{|c|}{ number concentration of particles $(1 / 1)$} \\
\hline$>0.3 \mu \mathrm{m}$ & 39,41 & 51,468 & 82,318 & 134,118 & 195,051 & 103,768 \\
\hline$>0.5 \mu \mathrm{m}$ & 4,026 & 5,313 & 8,755 & 21,84 & 36,044 & 15,66 \\
\hline$>1.0 \mu \mathrm{m}$ & 1,071 & 1,781 & 3,259 & 6,873 & 10,738 & 5,277 \\
\hline$>5.0 \mu \mathrm{m}$ & 25,3 & 37 & 59,3 & 92,7 & 130,3 & 80,2 \\
\hline \multicolumn{7}{|c|}{ mass concentration of particles $\left(\mu \mathrm{g} / \mathrm{m}^{3}\right)$} \\
\hline PM1 & 9,0 & 16,0 & 31,0 & 64,0 & 124,0 & 63,4 \\
\hline PM2.5 & 10,0 & 20,0 & 32,0 & 66,0 & 115,0 & 65,6 \\
\hline PM10 & 33,0 & 46,0 & 76,0 & 119,0 & 229,0 & 121,2 \\
\hline
\end{tabular}

* Measurements of total number concentration were carried out in 59 apartments, only.

to children not exposed to cigarettes or exposed to ETS from less than 5 cigarettes, only. PM1, PM2.5, and PM10 concentrations are also significantly higher at smoking of more than 5 cigarettes. Summarizing various potential exposure sources (e.g. high traffic density and smoking more than 5 cigarettes) increases the differences (data not shown).

High number concentrations $\left(>75^{\text {th }}\right.$ percentile or $>90^{\text {th }}$ percentile, respectively) of particles $>0.3$ or $>0.5 \mu \mathrm{m}$ showed an increased risk for the occurrence of bronchitis with fever (table 5). Strong risk increase was detected if PM1 and PM2.5 concentrations are high $\left(>75^{\text {th }}\right.$ percentile) or very high $\left(>90^{\text {th }}\right.$ percentile). The results are similar for obstructive bronchitis with fever (table 6). Assessing the risks for obstructive bronchitis with and without fever together also indicates that indoor mass concentrations of PM1 and PM2.5 are stronger associated to health risks than PM10 (data not shown). High number concentrations of particles $>1.0 \mu \mathrm{m}$ or $>5.0 \mu \mathrm{m}$, respectively, were not significantly associated to elevated health risks, as for these larger particles the mass concentration is more appropriate and a more powerful predictor of health effects.

For verification of the results we recalculated the odds ratios without randomly selected cases and with various slightly reduced sets of adjustment variables (number of persons living in the apartment, month of birth, gender of 
Table 4: Sources of indoor particles and related particle concentrations. (Significant differences according to Mann-Whitney's u-test are marked bold.)

\begin{tabular}{|c|c|c|c|c|c|c|c|}
\hline \multirow[t]{2}{*}{$\begin{array}{l}\text { Type of } \\
\text { particles }\end{array}$} & & \multicolumn{2}{|c|}{$\begin{array}{l}\text { Smoking } \\
\text { behavior }\end{array}$} & \multicolumn{2}{|c|}{$\begin{array}{l}\text { Number of } \\
\text { cigarettes }\end{array}$} & \multicolumn{2}{|c|}{$\begin{array}{l}\text { Children's room with } \\
\text { window to a street with } \\
\text { high traffic density }\end{array}$} \\
\hline & & daily & $\begin{array}{c}\text { seldom } \\
\text { or not }\end{array}$ & $>5$ & $0-5$ & yes & no \\
\hline \multirow{4}{*}{$>0.3 \mu \mathrm{m}$} & mean & 166,99 & 89,31 & 200,27 & 92,95 & 139,52 & 98,71 \\
\hline & $50 \mathrm{p}$. & 171,16 & 71,46 & 235,48 & 77,26 & 128,13 & 72,53 \\
\hline & $75 \mathrm{p}$. & 238,42 & 125,56 & 272,26 & 128,49 & 161,57 & 131,17 \\
\hline & $90 \mathrm{p}$. & 273,95 & 150,99 & 299,42 & 158,15 & 272,26 & 176,91 \\
\hline \multirow{4}{*}{$>0.5 \mu \mathrm{m}$} & mean & 30,61 & 12,24 & 38,62 & 13,09 & 23,31 & 14,58 \\
\hline & $50 \mathrm{p}$. & 30,23 & 7,59 & 36,68 & 7,68 & 22,43 & 8,25 \\
\hline & $75 \mathrm{p}$. & 45,13 & 15,99 & 54,38 & 16,92 & 34,86 & 18,3 \\
\hline & $90 \mathrm{p}$. & 54,58 & 29,07 & 56,77 & 31,43 & 51,71 & 33,17 \\
\hline \multirow{4}{*}{ PM1 } & mean & 158,8 & 41,6 & 234,9 & 44,2 & 112,8 & 56,4 \\
\hline & $50 \mathrm{p}$. & 58,5 & 27 & 129 & 29 & 46,5 & 29 \\
\hline & $75 \mathrm{p}$. & 183,5 & 53 & 200 & 56,5 & 115 & 60 \\
\hline & $90 \mathrm{p}$. & 292 & 81 & 825 & 87 & 200 & 103 \\
\hline \multirow{4}{*}{ PM2.5 } & mean & 158 & 44,5 & 231,4 & 47,1 & 119,6 & 58 \\
\hline & $50 \mathrm{p}$. & 65 & 28 & 107 & 29 & 46 & 29 \\
\hline & $75 \mathrm{p}$. & 184 & 60 & 204 & 62,5 & 128,5 & 64 \\
\hline & $90 \mathrm{p.}$ & 282 & 97 & 872 & 100 & 204 & 107 \\
\hline \multirow{4}{*}{ PM10 } & mean & 240,1 & 94 & 290,1 & 102,3 & 178,9 & 113 \\
\hline & $50 \mathrm{p}$. & 181 & 70 & 210 & 73,5 & 106 & 72 \\
\hline & $75 \mathrm{p}$. & 315,5 & 111 & 477 & 117 & 182 & 118 \\
\hline & $90 \mathrm{p}$. & 572 & 146 & 572 & 179 & 477 & 204 \\
\hline
\end{tabular}

child, atopic family anamnesis, and mould in the apartment). The similar odds ratios indicated real health risks, even at the rather small numbers of cases in the epidemiological analysis.

Measurements have been carried out on weekdays and in the daytime. During these times often one parent will not be present in the apartment. However, independent from this fact, we found significant correlations between smoking habits and measured particle concentrations. 
Table 5: $\quad$ Measured indoor particle concentrations and risk increase for bronchitis with fever ( $\mathrm{n}$ - number of cases) during the third year of life.

\begin{tabular}{|c|c|c|c|}
\hline $\begin{array}{l}\text { Analyzed } \\
\text { particle } \\
\text { fraction }\end{array}$ & $\begin{array}{c}\text { Low exposure } \\
\text { group } \\
(<75 \text { percentile) } \\
\text { n/ } / \mathbf{N}_{\text {low }}(\%)\end{array}$ & $\begin{array}{c}\text { High exposure } \\
\text { group } \\
(>75 \text { percentile) } \\
\text { n/ } / \mathbf{N}_{\text {high }}(\%)\end{array}$ & $\begin{array}{l}\text { Odds ratio } \\
( \pm 95 \% \text { CI })\end{array}$ \\
\hline \multicolumn{4}{|c|}{ particle number concentrations } \\
\hline$>0.3 \mu \mathrm{m}$ & $24 / 98(24.5 \%)$ & $13 / 31(41.9 \%)$ & $2.73(1.06-7.04)$ \\
\hline$>0.5 \mu \mathrm{m}$ & $25 / 96(26.0 \%)$ & $12 / 33(36.4 \%)$ & $1.83(0.73-4.58)$ \\
\hline$>1.0 \mu \mathrm{m}$ & $28 / 98(28.6 \%)$ & 9/31 (29.0\%) & $1.09(0.39-3.03)$ \\
\hline$>5.0 \mu \mathrm{m}$ & $27 / 96(28.1 \%)$ & $10 / 33(30.3 \%)$ & $1.10(0.45-2.68)$ \\
\hline \multicolumn{4}{|c|}{ particle mass concentrations } \\
\hline PM1 & $24 / 99(24.2 \%)$ & $13 / 30(43.3 \%)$ & $2.85(1.12-7.25)$ \\
\hline PM2.5 & $24 / 99(24.2 \%)$ & $13 / 30(43.3 \%)$ & $2.82(1.10-7.23)$ \\
\hline PM10 & $22 / 90(24.2 \%)$ & $15 / 39(38.5 \%)$ & $1.92(0.77-4.77)$ \\
\hline $\begin{array}{c}\text { Type of } \\
\text { particles }\end{array}$ & $\begin{array}{c}\text { Low exposure } \\
\text { group } \\
\text { (<90 percentile) } \\
\end{array}$ & $\begin{array}{c}\text { highest exposure } \\
\text { group } \\
\text { (>90 percentile) }\end{array}$ & $\begin{array}{l}\text { Odds ratio } \\
( \pm 95 \% \text { CI })\end{array}$ \\
\hline \multicolumn{4}{|c|}{ particle number concentrations } \\
\hline$>0.3 \mu \mathrm{m}$ & $32 / 118(27.1 \%)$ & $5 / 11(45.5 \%)$ & $2.39(0.60-9.52)$ \\
\hline$>0.5 \mu \mathrm{m}$ & $31 / 119(26.1 \%)$ & $6 / 10(60.0 \%)$ & $6.92(1.41-33.96)$ \\
\hline$>1.0 \mu \mathrm{m}$ & $33 / 119(27.7 \%)$ & $4 / 10(40 \%)$ & $2.69(0.59-12.32)$ \\
\hline$>5.0 \mu \mathrm{m}$ & $31 / 115(27.0 \%)$ & $6 / 14(42.9 \%)$ & $2.10(0.64-6.84)$ \\
\hline \multicolumn{4}{|c|}{ particle mass concentrations } \\
\hline PM1 & $31 / 120(25.8 \%)$ & $6 / 9(66.7 \%)$ & $5.94(1.24-28.59)$ \\
\hline PM2.5 & $31 / 119(26.1 \%)$ & $6 / 10(60.0 \%)$ & $5.57(1.25-24.78)$ \\
\hline PM10 & $29 / 113(25.7 \%)$ & $8 / 16(50 \%)$ & $3.48(1.07-11.35)$ \\
\hline
\end{tabular}

It has already been shown by earlier studies that indoor smoking increased risks for bronchitis and other respiratory diseases $[3,4,10,11]$. Our study may point to the fact that in particular particle exposure resulting from smoking contributes to bronchitis in children and not only gaseous components of ETS.

Traffic contributes considerably to urban outdoor exposure of various particle size fractions [10-12]. These particles also penetrate into the indoor environment due to ventilation, but also at closed windows [5]. Particle concentrations were 
significantly higher if children's rooms had windows to streets with high traffic density but not generally for apartments that were located in such streets.

Unfortunately, the influence of coal-burning for heating on the particle concentrations in the indoor air could not be investigated due to low case numbers. Heating with oil, gas or electricity did not result in significant increases of concentrations of all measured particle sizes.

Table 6: Measured indoor particle concentrations and risk increase for obstructive bronchitis with fever ( $\mathrm{n}$ - number of cases) during the third year of life.

\begin{tabular}{|c|c|c|c|}
\hline $\begin{array}{l}\text { Type of } \\
\text { particles }\end{array}$ & $\begin{array}{c}\text { Low exposure } \\
\text { group } \\
\text { (<75 percentile) } \\
\text { n/Nlow }(\%)\end{array}$ & $\begin{array}{c}\text { High exposure } \\
\text { group } \\
\text { (>75 percentile) } \\
\text { n/Nhigh }(\%)\end{array}$ & $\begin{array}{l}\text { Odds ratio } \\
(+95 \% \text { CI })\end{array}$ \\
\hline \multicolumn{4}{|c|}{ particle number concentrations } \\
\hline$>0.3 \mu \mathrm{m}$ & $10 / 97(10.3 \%)$ & $7 / 31(22.6 \%)$ & $2.52(0.78-8.20)$ \\
\hline$>0.5 \mu \mathrm{m}$ & $10 / 95(10.5 \%)$ & $7 / 33(21.21 \%)$ & $2.46(0.76-7.98)$ \\
\hline$>1.0 \mu \mathrm{m}$ & $12 / 97(12.4 \%)$ & $5 / 31(16.1 \%)$ & $1.21(0.31-4.69)$ \\
\hline$>5.0 \mu \mathrm{m}$ & $13 / 96(13.5 \%)$ & 4/32 (12.1\%) & $0.94(0.28-3.24)$ \\
\hline \multicolumn{4}{|c|}{ particle mass concentrations } \\
\hline PM1 & $8 / 98(8.2 \%)$ & $9 / 30(30.0 \%)$ & $5.32(1.66-17.11)$ \\
\hline PM2.5 & $8 / 98(8.2 \%)$ & $9 / 30(30.0 \%)$ & $5.55(1.69-18.24)$ \\
\hline PM10 & $8 / 89(9.0 \%)$ & $9 / 39(23.1 \%)$ & $3.10(0.94-10.19)$ \\
\hline $\begin{array}{c}\text { Type of } \\
\text { particles }\end{array}$ & $\begin{array}{c}\text { Low exposure } \\
\text { group } \\
(<90 \text { percentile }) \\
\text { n/ } / \mathbf{N}_{\text {low }}(\%) \\
\end{array}$ & $\begin{array}{c}\text { Highest exposure } \\
\text { group } \\
(>90 \text { percentile }) \\
\text { n/ } \mathbf{N}_{\text {high }}(\%) \\
\end{array}$ & $\begin{array}{l}\text { Odds ratio } \\
( \pm 95 \% \text { CI })\end{array}$ \\
\hline \multicolumn{4}{|c|}{ particle number concentrations } \\
\hline$>0.3 \mu \mathrm{m}$ & 13/117 (11.1\%) & $4 / 11(36.4 \%)$ & $4.81(1.03-22.41)$ \\
\hline$>0.5 \mu \mathrm{m}$ & $12 / 118(10.2 \%)$ & $5 / 10(50.0 \%)$ & $22.07(3.45-141.2)$ \\
\hline$>1.0 \mu \mathrm{m}$ & $14 / 118(11.9 \%)$ & $3 / 10(30.0 \%)$ & $5.02(0.87-28.82)$ \\
\hline$>5.0 \mu \mathrm{m}$ & $15 / 114(13.2 \%)$ & $2 / 14(14.3 \%)$ & $1.17(0.23-5.99$ \\
\hline \multicolumn{4}{|c|}{ particle mass concentrations } \\
\hline PM1 & $12 / 119(10.1 \%)$ & $5 / 9(55.6 \%)$ & $11.62(2.29-58.99)$ \\
\hline PM2.5 & $12 / 118(10.2 \%)$ & $5 / 10(50.0 \%)$ & $9.73(2.04-46.46)$ \\
\hline PM10 & $12 / 112(10.7 \%)$ & $5 / 16(31.3 \%)$ & $4.15(1.07-16.13)$ \\
\hline
\end{tabular}


Epidemiological studies addressed to indoor particle exposure need a high number of measurements. Such measurements can typically not be carried out over long times. In our study we had no possibility to repeat the measurements or to measure over long times. Therefore, we paid strong attention to the measuring conditions. Epidemiological studies with similar measurements may be subject to similar restrictions. Hence, an important aim of this study was to test the power of such measurements for detection of exposure differences which can be related to significantly varying health risk. Short-term measurements are not able to assess the exact mean exposure of one selected child. But, they may be a reliable tool in epidemiologic studies with sufficient numbers of participants.

\section{References}

[1] Brasche S, Bischof W. Daily time spent indoors in German homesbaseline data for the assessment of indoor exposure of German occupants. Int J Hyg Environ Health 208, pp. 247-253, 2005.

[2] Delfino, R.J., Staimer, N., Gillen, D., Tjoa, T., Sioutas, C., Fung, K., George, S.C. \& Kleinman, M.T. Personal and ambient air pollution is associated with increased exhaled nitric oxide in children with asthma. Environ. Health Perspect., 114, pp. 1736-1743, 2006.

[3] Kabir Z, Manning PJ, Holohan J, Keogan S, Goodman PG, Clancy L. Second hand smoke exposure in cars and respiratory health effects in children. Eur Respir J 34, pp. 629-633 2009.

[4] Schwartz J. Particulate air pollution and chronic respiratory disease. Environ Res 62, pp. 7-13, 1993.

[5] Wong TW, Yu TS, Liu HJ, Wong AH. Household gas cooking: a risk factor for respiratory illnesses in preschool children. Arch Dis Child 89, pp. 631636, 2004.

[6] Wallace LA, Emmerich SJ, Howard-Reed C. Source strengths of ultrafine and fine particles due to cooking with a gas stove. Environ Sci Technol 38, pp. 2304-2311, 2004.

[7] Franck U, Tuch T, Manjarrez M, Wiedensohler A, Herbarth O. Indoor and outdoor submicrometer particles: exposure and epidemiologic relevance ("the 3 indoor Ls"). Environ Toxicol 21, pp. 606-613, 2006.

[8] Borte M, et al. Influence of lifestyle and behaviour on the development of the immune system and allergic diseases. In: Schulz R, Lehmann I, editors. The LISA birth cohort study, 3. Public Health Research and Practice 2001. pp. 60-77, 2001.

[9] Brockow I, Zutavern A, Franke K, Schaaf B, von Berg A, Kramer U, et al. Influences of lifestyle-related factors on the immune system and the development of allergies in childhood (LISA). Design and results to date of a prospective birth cohort study. Monatsschrift Kinderheilkunde 156, pp. 249-255, 2008.

[10] Horak E, Morass B, Ulmer H. Association between environmental tobacco smoke exposure and wheezing disorders in Austrian preschool children. Swiss Med Wkly 137, pp. 608-613, 2007. 
[11] Marbury MC, Maldonado G, Waller L. The indoor air and children's health study: methods and incidence rates. Epidemiology 7, pp. 166-74, 1996.

[12] Harrison RM, Jones AM. Multisite study of particle number concentrations in urban air. Environ Sci Technol 39, pp. 6063-70, 2005.

[13] Morawska L, Jamriska M, Thomas S, Ferreira L, Mengersen K, Wraith D, et al. Quantification of particle number emission factors for motor vehicles from on-road measurements. Environ Sci Technol 39, pp. 9130-9139, 2005.

[14] Tuch TM, Herbarth O, Franck U, Peters A, Wehner B, Wiedensohler A, et al. Weak correlation of ultrafine aerosol particle concentrations b800 nm between two sites within one city. J Expo Sci Environ Epidemiol 16, pp. 486-490, 2006. 